\title{
Short day photoperiod protects against acetaminophen-induced heptotoxicity in rats
}

\author{
Olayaki, L. A. ${ }^{1}$, Abduraheem, T. A. ${ }^{1}$, Mbukanma, O. E. ${ }^{1}$, Agbede, O. O. ${ }^{1}$, \\ Salman, T. M. ${ }^{1}$ and Ojo, O. $0^{2}$ \\ ${ }^{1}$ Department of Physiology, Faculty of Basic Medical Sciences, College of Health Sciences, University of \\ Ilorin, Ilorin. ${ }^{2}$ School of Biomedical Science, University of Ulster, Coleraine, United Kingdom
}

\begin{abstract}
This study investigated the effect of different photoperiods on acetaminophen-induced hepatotoxicity in rats. Twenty four adult male rats (average weight $=160 \pm 7 \mathrm{~g}$ ) were conditioned to different photoperiod regimens for 6 weeks. At the end of the 6-week period, rats exposed to normal, short and long photoperiods received oral acetaminophen $(2 \mathrm{~g} / \mathrm{kg}$ body weight) while in the control group, exposed to normal photoperiod, received oral saline. Rats were sacrificed $24 \mathrm{~h}$ after acetaminophen administration by cervical dislocation and blood was collected by cardiac puncture for the estimation of liver enzymes activities. Liver tissues were excised and homogenized for estimation of liver malondialdehyde (MDA) concentration. Elevation of serum levels of alanine and aspartate transaminases and alkaline phosphatase caused by acetaminophen intoxication were not affected in rats subjected to long photoperiod while these parameters were significantly $(P<0.05)$ reduced in rats subjected to short photoperiod. However, alteration of photoperiod resulted in significantly $(P<0.05)$ lower serum gamma glutamate transpeptidase and total protein in acetaminophentreated rats. All groups of rats had similar serum albumin while serum malondialdehyde concentration was significantly lower in rats subjected to short photoperiod. This study revealed the protective effects of short photoperiod against acetaminophen-induced hepatotoxicity and lipid peroxidation in rats.
\end{abstract}

(Received 15:06:15; Accepted 20:06:15)

Key words: Acetaminophen, photoperiod, lipid peroxidation, Hepatotoxicity

Correspondence: o.ojo@ulster.ac.uk

\section{Introduction}

Studies have shown that short day lengths generally enhance many types of immune responses in the laboratory animals (Nelson, 2004; Olayaki et al., 2008). Increased cellmediated immune responses including lymphocyte proliferation to mitogens, delayed-type hypersensitivity responses and overall numbers of circulating immune cells have been reported as a consequence of exposure to short day length (Blom et al., 1994; Demas and Nelson, 1996; Demas and Nelson, 1998; Bilbo et al., 2002). Photoperiodic adjustment in immune defences is mediated almost entirely by the pineal melatonin rhythm. Melatonin, a hormone produced by a wide range of organism including animals, plants and microbes, has been reported for its antiinflammatory and immune enhancing actions in laboratory animals (Maestroni et al., 1987; Guerrero and Reiter, 2002). Its effects as a free radical scavenging agent have also been reported
(Tan et al., 2002; Reiter et al., 2002; Rodriquez et al., 2004). Previous studies have shown that melatonin exhibited hepatoprotective effect by reducing the generation of reactive oxygen species and lipid peroxidation (Kanno et al., 2006). Mathes (2010) showed that hepatoprotective effect of melatonin was mediated by melatonin receptors that present in the hepatocytes. Although melatonin is synthesized in a number of tissues such as retina, GIT, lymphocytes, circulating melatonin in mammals is largely derived from the pineal gland (Cardinali and Pevet, 1998). Pineal melatonin production exhibits a circadian rhythm, with a low level during daytime and high levels during night (Claustrat et al., 2005).

This study, investigated the effect of changes in photoperiod exposure on liver enzymes and lipid peroxidation following acetaminophen hepatotoxicity in rats. Paracetamol (acetaminophen), widely used 
antipyretic and analgesic, is mainly metabolised in the liver to excretable glucoronide and sulphate conjugates (Jallow et al., 1974; Wong et al., 1981). Despite this therapeutic usage, hepatotoxic actions of acetaminophen are well established (J ames et al., 2003). Acetaminophen is converted in the presence of cytochrome P-450 to its reactive metabolite, $\mathrm{N}$-acetyl-p-benzoquinone imine (NAPQI), which covalently binds to cysteine to form a conjugate with glutathione to deplete glutathione stores. This results in the accumulation of NAPQI and mitochondrial dysfunction leading to the development of acute hepatic necrosis in liver centrolobular cells (J aeschke et al., 2002). Though the hepatoprotective effect of melatonin is wellestablished, the relationship between photoperiods and the protective actions of melatonin is not well understood. Therefore, this study was carried out to determine how different photoperiods affect the hepatoprotective action of melatonin in acetaminophen-induced liver damage in rats.

\section{Materials and Methods}

Experimental animals: Twenty four male Sprague Dawley rats were obtained from the Animal Breeding Unit of the Department of Biochemistry, University of Ilorin, Ilorin, Nigeria. The rats weighed $160 \pm 7 \mathrm{~g}$ and were conditioned to different light conditions for 6 weeks. All animals were housed in plastic cages with stainless steel mesh cover under standard laboratory conditions in photoperiod-controlled chambers. Lighting in photoperiod chambers was provided by 6-watt fluorescent tubes at illuminance of 100-250 lux located at $5 \mathrm{~cm}$ above each cage. The experiment was conducted during the raining season. Rats pellet (Bendel Feeds, Edo State, Nigeria) and water were provided ad libitum. All experimental procedures were approved by the Animal Ethical Committee of the Faculty of Basic Medical Sciences, University of Ilorin.

Experimental design: Animals were divided into 4 groups $(n=6)$ and subjected to photoperiodic conditions of light/dark cycle as shown in Table 1 for 6 weeks. At the end of the treatment period, rats in groups II, III and IV received oral administration of $2 \mathrm{~g} / \mathrm{kg}$ body weight of acetaminophen (Mayer and Baker Nigeria PLC, Ota, Ogun State, Nigeria) suspension in normal saline as previously described (Rajesekaran and Periyasamy, 2012; Rekha et al., 2013). The rats were sacrificed $24 \mathrm{hr}$ after acetaminophen administration by cervical dislocation. Blood samples were collected by cardiac puncture and serum separated by centrifugation. Liver of sacrificed animals were excised immediately and homogenized for the determination of tissue concentration for malondialdehyde.

Table 1: Photoperiod exposure of normal and acetaminophen-treated rats

\begin{tabular}{lllll}
\hline Groups & $\begin{array}{l}\text { Saline } \\
\text { Control }\end{array}$ & $\begin{array}{l}\text { Acetaminophen } \\
\text { Control }\end{array}$ & Long Photoperiod & $\begin{array}{l}\text { Short } \\
\text { Photoperiod }\end{array}$ \\
\hline Light/Dark Cycle (hrs) & $12: 12 \mathrm{~h}$ & $12: 12 \mathrm{~h}$ & $16: 8 \mathrm{~h}$ & $8: 16 \mathrm{~h}$ \\
Time of the day & $07: 00-19: 00 \mathrm{~h}$ & $07: 00-19: 00 \mathrm{~h}$ & $05: 00-21: 00 \mathrm{~h}$ & $09: 00-17: 00 \mathrm{~h}$ \\
\hline
\end{tabular}

Rats in acetaminophen control group as well as long and short photoperiod groups received a single oral administration of $2 \mathrm{~g} / \mathrm{kg}$ body weight of acetaminophen following 6 weeks exposure to different photoperiods

Assessment of liver enzyme activities: Serum activities of alanine aminotransferase (ALT), alkaline phosphate (ALP), aspartate aminotransfrase (AST) and gamma glutamate transpeptidase (GGT) as well as concentrations of total protein and albumin levels were measured using the commercially available assay kits (Agape Diagnostics, Switzerland Gmbh) following the manufacturer's recommended procedures.. Assays performed using an automated blood chemistry analyser (URIT-810 Chemistry Analyzer, URIT Medical Electronic Co., Ltd. Guangxi, PR China).

Assessment of lipid peroxidation: Tissue malonaldedyde (MDA) levels were estimated as described by Ohkawa et al, (1979). Tissues were homogenized in ice cold $\mathrm{KC}(100 \mathrm{mM})$ containing
0.003M EDTA ( $3 \mathrm{ml}$ ) and centrifuged at $600 \mathrm{~g}$ for $15 \mathrm{~min}$. Aliquots of supernatant $(400 \mu \mathrm{l})$ were added to a solution containing $8.1 \%$ SDS, $20 \%$ acetic acid (pH 3.5), $0.8 \%$ thiobarbituric acid and $0.6 \mathrm{ml}$ water and heated at $95^{\circ} \mathrm{C}$ for 60 minutes. This was followed by the addition of $1.0 \mathrm{ml}$ water and $5.0 \mathrm{ml}$ of n-butanol-pyridine mixture (15:1, $\mathrm{vol} / \mathrm{vol}$ ). The mixture was vigorously shaken and centrifuged at $2,000 \mathrm{~g}$ for 15 minutes. The absorbance of the upper layer was read at 532nm using an AcurexMicroplate Reader. Malondialdehydebis-dimethyl acetal was used as the external standard and results were expressed as nanomoles MDA per milligram protein. The intra-assay variability was determined in five sets of triplicate samples and the coefficient of variation given.

Statistical Analysis: Data were analysed using GraphPad Prism Version 3 and expressed as mean \pm SEM. More than two variables were compared by using one-way ANOVA test and 
Duncan's test was performed for post-hoc analysis.

\section{Results}

Effects of photoperiods on serum levels of liver function parameters in acetaminophentreated rats: Administration of acetaminophen resulted in marked elevation of serum levels of AST $(496 \%, P<0.001)$, ALT $(389 \%, P<0.001)$, ALP (99\%, P<0.001) and GGT(255\%, P<0.001) compared with control animals treated with saline (Figure 1). Exposure to long photoperiod (16:8, light:dark hr) produced no significant effect on serum levels of AST , ALT and ALP but inhibited increased serum levels of GGT caused by acetaminophen administration by $26 \%(P<0.05)$. However, significant reduction in serum levels of AST $(40 \%, \mathrm{P}<0.01)$, ALT $(28 \%, \mathrm{P}<0.05)$ and GGT (74\%, P<0.001) and no change in serum ALP were observed in rats exposed to short photoperiod. Serum total protein increased by 5fold $(P<0.001)$ in acetaminophen-treated rats compared with their saline-treated counterparts (Figure 1E). This increase was reduced by $37 \%$ $(P<0.05)$ and $46 \% \quad(P<0.05)$ in rats exposed to long and short photoperiods respectively. However, similar serum levels of albumin was observed in all groups of rats (Figure $1 \mathrm{~F}$ ).

Figure 1.
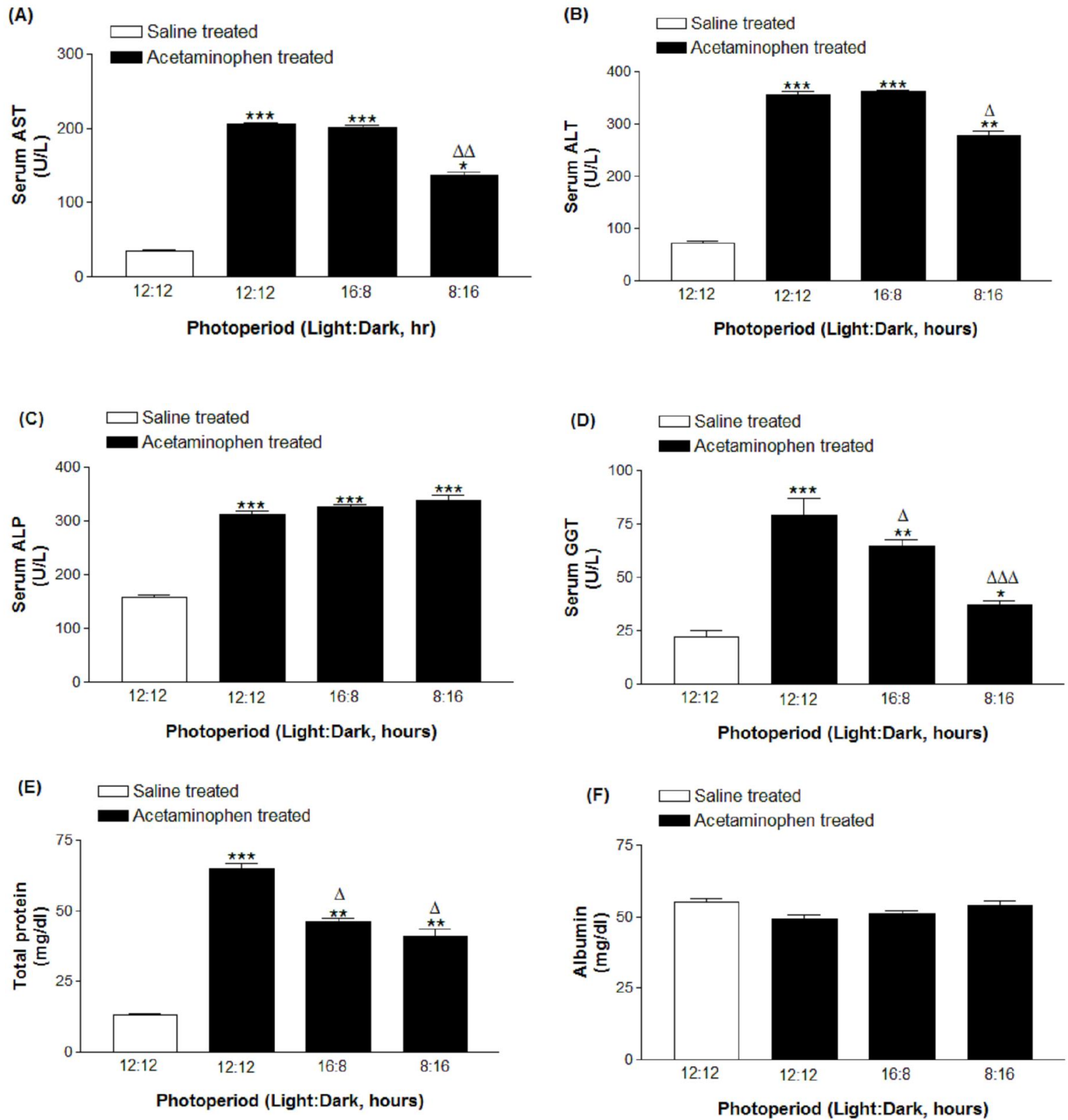

Figure 1: Effects of different photoperiods on serum levels of $(A)$ aspartate transaminase, (B) alanine transaminase, $(C)$ alkaline phosphatase, $(D)$ gamma glutamate transpeptidase, $(E)$ total protein and $(F)$ albumin in rats with acetaminophen-induced hepatotoxicity. Values are mean \pm SEM with $n=6 . * P<0.05$, $* * P<0.01$ and $* * * P<001$ compared with saline treated rats exposed to 12:12 light:dark photoperiod. ${ }^{\Delta} \mathrm{P}<0.05,{ }^{\Delta \Lambda} \mathrm{P}<0.01,{ }^{\triangle \Lambda \Delta} \mathrm{P}<0.001$ compared with acetaminophen treated rats exposed to $12: 12$ light: dark photoperiod. 
Effects of photoperiods on lipid peroxidation in acetaminophen-treated rats: Basal serum malondialdehyde concentration in salinetreated rats exposed to $12 \mathrm{~h}$ light and $12 \mathrm{~h}$ dark cycle was $172.5 \mathrm{mmol} / \mathrm{mg}$ proteins. This value was increased by 2.1 -fold $(P<0.001)$ in acetaminophen-treated rats under similar experimental conditions (Figure 2). Exposure to long photoperiod had not significant effect on serum concentration of malondialdehyde but rats maintained under short photoperiod showed a $35 \% \quad(P<0.05) \quad$ reduction in serum malondialdehyde level.

Figure 2 .



Figure 2: Effects of different photoperiods on serum levels of malondialdehyde in rats with acetaminopheninduced hepatotoxicity. Values are mean \pm SEM with $n=6$. $* * P<0.01$ and $* * * P<001$ compared with saline treated rats exposed to $12: 12$ light: dark photoperiod. ${ }^{\Delta} \mathrm{P}<0.05$, compared with acetaminophen treated rats exposed to 12:12 light: dark photoperiod.

\section{Discussion}

Acetaminophen containing drugs are commonly used globally for the treatment of pain and fever (Kaufman et al, 2002). Despite this important therapeutic utility, studies have shown that its consumption at doses exceeding the maximum recommended dose of $4 \mathrm{~g} /$ day could result to serious liver injury or death in humans (Watkins and Seef, 2006). Studies in laboratory animals have also confirmed that administration of acetaminophen at doses in excess of $2 \mathrm{~g} / \mathrm{kg}$ body weight could result in significant liver injury (Madkour and Abdel-Daim, 2013). These reports are consistent with public health concerns raised by the increasing incidence of acetaminophenrelated liver injury over the past few years (Kaufman et al, 2002). Acetaminophen is converted to its toxic metabolite, $\mathrm{N}$-acetyl- $\mathrm{P}$ benzoquinone imine. This oxidation product of acetaminophen binds to sulphydryl groups of protein in the liver to induce cell necrosis and lipid peroxidation caused by decreased hepatic gluthathione levels (Boyd et al., 1966).I ncrease in circulating concentrations of liver enzymes (ALT and AST), which are of cytoplasmic origin, is indicative of hepatic injury (Drotman et al, 1978). Increased serum ALP and Y-glutamyl transpeptidase levels, resulting from increased
ALP synthesis in the presence of increasing biliary pressure, has been recognized as a more specific and sensitive biomarkers of liver injury (Muriel and Garcipiana, 1992).

In this study, rats intoxicated with acetaminophen exhibited characteristics features that are consistent with previous reports of its ability to induce liver damage (Galal et al, 2012; Madkour and Abdel-Daim, 2013). Serum levels of AST, ALT, ALP and GGT were significantly elevated in rats intoxicated with acetaminophen under normal 12:12 light:dark photoperiods. This impaired liver function is also accompanied with elevated serum levels of malondialdehyde, which suggests increased lipid peroxidation. Increased lipid peroxidation in acetaminophen toxicity is believed to be a consequence of increased interaction between cellular lipids and acetaminophen metabolites (Albano et al, 1983). This observation is consistent with previous studies reporting decreased cellular reduced glutathione activities, increased malondialdehyde production and promotion of lipid productions in both in vitro and in vivo models of acetaminophen-hepatotoxicity (Fairhurst et al, 1982; Albano et al, 1983).

The result of this study has clearly shown that altering photoperiod effectively protects 
against the deleterious effects of acetaminophen on the liver. Our results indicated that increasing light period from 12 to 16 hours daily produced no significant effect on the serum concentrations of AST, ALT or ALP but produced a significant reduction in the circulating concentrations of GGT and reduced the production of malondialdehyde. However, a more pronounced inhibition of the deleterious effects of acetaminophen, exemplified by significant reduction in serum concentrations of liver enzyme and malondialdehyde was observed in rats treated with 8 hours of light and 12 hours of dark period for 6 weeks prior to acetaminophen intoxication. Results obtained in rats subjected to $8: 12$ light:dark period are in agreement with previous studies indicating a reduction in serum levels of liver enzyme and malondialdehyde with reduced acetaminopheninduced hepatotoxicity and lipid peroxidation in vivo (Madkour and Abdel-Daim, 2013).

Though the exact mechanism by which changes in photoperiod affect acetaminopheninduced hepatotoxicity is not yet fully understood, several studies have reported the effect of changes in photoperiod on signal transduction in animals (reviewed in Dahl et al, 1999). Studies have shown that photoperception occurs in the retina in mammals, leading to the stimulation of retinal photoreceptors which send inhibitory signals to the pineal gland and modulate its secretion of several hormones, including melatonin (Reiter, 1991). Studies have shown that light inhibits the activity of $\mathrm{N}$-acetyltransferase, the rate-limiting enzyme in melatonin synthesis (Illnerova and Sumova, 1997). This observation suggests that the reduction of light phase from 12 hto $8 \mathrm{~h}$ in this study may be accompanied by increased melatonin secretion. In addition to its ability to regulate the sleep/wake cycle in mammals, antioxidant and anti-inflammatory effects of melatonin have also been reported (Esposito and Cuzzocrea, 2010; Morcelli et al, 2013). Li et al (2014) also reported that melatonin protects against hepatic ischemia/reperfusion injury in clinical liver disease.

Melatonin binds to melatonin receptor 1 or 2 to elicit downstream signalling cascades with various physiologic effects. Melatonin receptors are $\mathrm{G}$ protein-coupled receptors which are expressed in various tissues of the body, including several parts of the central nervous system (CNS), ovary, retina, testis, mammary gland, coronary circulation and aorta, gall bladder, kidney, skin, adpocytes and the liver (Sallinen et al, 2005, Mathes et al, 2008). The activation of melatonin receptor type $1 \mathrm{~A}$ by melatonin or melatonin receptor agonists leads to the inhibition of the CAMP signalling pathway via the inactivation of adenylate cylcase followed by reduced protein kinase A (PKA) activity and decreased generation of phosphorylated CAMP responsive elementbinding protein (P-CREB) (Boutin et al, 2005; $\mathrm{Ma}$ et $\mathrm{al}, 2008$ ). In addition, the activation of melatonin receptor 1 potentiates the release of arachidonate following the activation of phospholipase $\mathrm{C}$ and regulate ion flux inside the cell ( $\mathrm{Ma}$ et al, 2008). The activation of melatonin receptor type 2 inhibits adenylyl cyclase s well as guanylyl cyclase and therefore affects the production of both CAMP and cyclic guanosine monophosphate (cGMP) (Hattori et al, 1995; Ma et al, 2008). Though the molecular mechanisms through which melatonin exerts its protective effects against acetaminophen intoxication as observed in this study is not yet clear, we hypothesize that the expression of melatonin receptors in rat liver may play a significant role. We also hypothesize that during the short photoperiod, melatonin secretion is increased in rats used in this study over the six weeks period. This elevated melatonin concentration resulted in enhanced protection of these animals against acetaminophen-induced lipid peroxidation and liver damage.

Consistent with previous studies (Yakubu et al, 2013), oral administration of acetaminophen has no significant effect on serum albumin level but resulted in significantly elevated serum total protein concentration. This result negates the usual observation of reduced serum protein in liver damage (Oyagbemi and Odetola et al, 2010; Ekam et al, 2012) and strongly suggests that the administration of acetaminophen in this study may affect metabolic processes such as bone marrow development and the development of other conditions such as multiple myeloma, which contribute to elevated serum protein ( $\mathrm{O}^{\prime}$ Connell et al, 2005; Walter et al, 2011). Changes in photoperiod examined in this study did not affect serum albumin levels. However, reduced total serum protein were observed in rats exposed to long photoperiod while increased total serum protein was observed in rats exposed to short photoperiod. Increased serum total protein has been reported in hepatic damage (Melligen and Wergeland, 2000). However, it is not yet clearly understood how changes in photoperiod affect serum protein in acetaminophen-induced hepatotoxicity.

\section{Conclusion}

In conclusion, this study have shown that exposure to short photoperiod for 6 weeks offer some protection against acetaminophen-induced lipid peroxidation and liver damage in rats via a mechanism that is believed to involve enhanced production of melatonin. This observation encourages further investigations of melatoninmediated roles in the protection against liver injury by short photoperiod as a way of identifying its therapeutic utility. 


\section{Conflict of I nterests}

Authors declare no conflict of interests.

\section{References}

Albano, E., Poli, G., Chiarpotto, E., Biasi, F. and Dianzani M.U. (1983). Paracetamol-stimulated lipid peroxidation in isolated rat and mouse hepatocytes. Chem. Biol. Interact. 47: 249-263

Bibo, S.B., Dhabhar, T.S., Viswanathan, K., Saul, A., Yellon, S.M. and Nelson, R.J. (2002). Study day length auguments stress-induced leukocytes trafficking and stress induced enhancement of skin immune functions. Proc. Natl. Accd. Sci. USA. 99: 4067-4072

Blom, J.M., Gerber, J.M. and Nelson, R.J. (1994). Day length affects immune cells numbers in deer mice, interactions with sex, age and prenatal photoperiod. Am. J. Physiol.267: 596-601

Boutin, J. A., Audinot, V., Ferry, G., Delagrange, P. (2005). Molecular tools to study melatonin pathways and actions. Trends Pharmacol Sci. 26: 412-419

Boyd, E.M. and Bereczky,G.M.(1996). Liver necrosis from paracetamol. $\mathrm{Br}$ J. Pharmacol. 26: 606-614

Cardinali, D.P. and Pevet, P. (1998). Basic aspects of melatonin action. Sleep Med. Rev.2: 175-190.

Claustrat, B., Brun, J. and Chazot, G. (2005). The basic physiology and pathophysiology of melatonin. Sleep Med. Rev. 9: 11-24.

Dahl, G.E., Buchanan, B.A. and Tucker, H.A. (2000). Photoperiodic effects on dairy cattle: a review. J. Dairy Sci. 83: 885-893.

Demas, G.T. and Nelson, R.J . (1996). Photoperiod and temperature interact to affect immune parameters in adult male deer mice (Peronyscus mariculatus). J. Biol. Rhythms 11: 94-102.

Demas, G.T. and Nelson, R.J. (1998). Exogenous melatonin enhances cell-mediated but not humoral immune function in adult male deer mice (peronyscusmaniculatus). J. Biol. Rhythm 13: 245-252.

Drotman, R. and Lawhan, G. (1978). Serum enzymes are indications of chemical induced liver damage. Drug Chem. Toxicol. 1:163-71.

Esposito, E. and Cuzzocrea, S. (2010). Antiinflammatory activity of melatonin in central nervous system. Curr. Neuropharmacol. 8: 228242.

Ekam, V. S., J ohnson, J. T., Dasofunjo, K., Odey, M. O. and Anyahara, S.E. (2012). Total protein, albumin and globulin levels following the administration of activity directed fractions of Vernonia amygdalina during acetaminophen induced hepatotoxicity in wistar rats Annals of Biol. Res. 3:5590-5594

Fairhurst, S., Barber, D.J., Clark, B. and Horton, A.A. (1982). Studies on paracetamol-induced lipid peroxidation. Toxicology 23: 249-259.

Galal, R.M., Zaki, H.F., Seif El-Nasr, M.M. and Agha, A.M. (2012). Potential protective effect of honey against paracetamol-induced hepatotoxicity. Arch. I ran Med. 15:674-680.

Guerrero, J.M. and Reiter, R.J. (2002). Melatonin immune system relationships. Curr. Top. Med. Chem. 2: 167-179.

Hattori, A., Migitaka, H., ligo, M., Itoh, M., Yamamoto, K., Ohtani-Kaneko, R., Hara, M., Suzuki, T., Reiter, R. J. (1995). Identification of melatonin in plants and its effects on plasma melatonin levels and binding to melatonin receptors in vertebrates. Biochem Mol Biol Int. 35:627-634

Illnerova, H. and Sumova, A. (1997). Photic entrainment of the mammalian rhythm in melatonin production. J. Biol. Rhythms 12: 547555.

J easchke, H., Gomes, G.J., Cederbaum, A.I., Hinson, J.A., Dominique, P. and Lemaster, J.J. (2002). Mechanisms of hepatotoxicity. Toxicol. Sci. 65: 166-176.

Jallow, D.J., Thorgeirsson, S.S., Potter, W.Z, Hashimoto, M. and Mitchell, J.R. (1974). Acetaminophen-induced hepatic necrosis. VI. Metabolic disposition of toxic and non-toxic doses of acetaminophen. Pharmacology 12: 251-271.

James, L.P., Philip, R., Mayeu, X. and Hinson, J.A. (2003). Acetaminophen-induced hepatotoxicity. Soc. Pharmaco. Exp. Therap.31: 1499-150

Kanno, S. Tomizawa, A., Hiura, T., Osanai, Y., Kakuta, M., Kitajima, Y., Koiwai, K., Ohtake, T., Ujibe, M. and Ishikawa, M. (2006). Melatonin protects on toxicity by acetaminophen but not on pharmacological effects in mice. Biol Pharm Bull. 29(3): 472-476.

Kaufman, D.W., Kelly, J.P., Rosenberg, L., Anderson, T.E. and Mitchell, A.A. (2002). Recent patterns of medication use in the ambulatory adult population of the United States: the Slone survey. JAMA 287: 337-44.

Li, Y., Yang, Y., Feng, Y., Yan, J., Fan, C., Jiang, S. and Qu, Y. (2014).A review of melatonin in hepatic ischemia/reperfusion injury and clinical liver disease. Ann Med. 46: 503-511.

Ma, X., Chen, C., Krausz, K. W., I dle, J. R., Gonzalez, F. J. (2008). A metabolomic perspective of melatonin metabolism in the mouse. Endocrinology 149:1869-1879.

Madkour, F.F. and Abdel-Daim, M.M. (2013). Hepatoprotective and antioxidant activity of 
Dunaliella salina in paracetamol-induced acute toxicity in rats. Indian J. Pharm. Sci. 75: 642-648.

Maestoni, G.J., Carti, A. and Pierpaoli, U.S. (1987). The pineal gland and the circadian opictergernic, immuniregulatory role of melatonin. Ann N Y Acad. Sci. 496: 67-99.

Mathes, A. M., Kubulus, D., Weiler, J., Bentley, A., Waibel, L., Wolf, B., Bauer, I., Rensing, H. (2008). Melatonin receptors mediate improvements of liver function but not of hepatic perfusion and integrity after hemorrhagic shock in rats. Crit Care Med. 36(1):24-29.

Mathes, A.M. (2010). Hepatoprotective actions of melatonin: possible mediation by melatonin receptors. World J Gastroenterol. 16(48): 608797.

Mellingen, G.O. and Wergeland, H.I. (2000). Serum protein and IgM profiles in connection with the smolting and vaccination of out-of-season Atlantic salmon (Salmo salar L.). Aquaculture 188: 189-201.

Morceli, G., Honorio-França, A.C., Fagundes, D.L., Calderon, I.M. and França, E.L. (2013). Antioxidant effect of melatonin on the functional activity of colostral phagocytes in diabetic women.PLoS One. 8(2):e56915doi: 10.1371/journal. pone. 0056915

Muriel, P. and Garcipiana, T. (1992). Silymarin protects against paracetamol-induced lipid peroxidation and liver damage. J. Appl. Toxicol. 12: 439-442.

Nelson, R.J. (2004). Seasonal immune function and sickness responses. Trend Immunol 25: 187192.

Nelson, R.J . and Demas G.E. (1996). Seasonal changes in immune function. Quart Rev Biol 71: 511.

O'Connell, T.X., Horita, T. J., and Kasravi, B. (2005). Understanding and interpreting serum protein electrophoresis. Am Fam Physician. 71:105-112.

Ohkawa, H., Ohishi, N. and Yagi, K. (1979). Assay for lipid peroxides in animal tissues by thiobarbituric acid reaction. Anal Biochem. 95: 351-358.

Olayaki, L.A., Salman, T.M., Jimoh, A.A.G., Iduh, G. and Soladoye, A.O. (2008). Effects of photoperiod on some haematological indices in rats. Nig. J. Health Biomed. Sci. 7: 11-14.

Oyagbemi, A. A. and Odetola A. A. (2010). Hepatoprotective effects of ethanolic extract of Cnidoscolus aconitifolius on paracetamol-induced hepatic damage in rats. Pak J Biol Sci. 13(4):1649.

Rajesekaran, A. and Periyasamy, M. (2012). Hepatoprotective effect of ethanolic extract of Trichosanthes lobata on paracetamol-induced liver toxicity in rats. Chin Medicine 7:12.

Rieter, R.J. (1991). Pineal melatonin: cell biology of its synthesis and of its physiological interactions. Endocrine Rev. 12: 151-180.

Reiter, R.J., Tan, D.X., Manchester, L.C. and Calvo, J.R. (2002). Antioxidative capacity of melatonin. In handbook of antioxidants, $2^{\text {nd }} e d n$. Cadenas E. Packer I, ed. Pp 565-613. Marcel Dekker, New York

Rekha, S.S., Sowjanya, P., Rao N.S., Govinda, G. and Babu, N.G. (2013). Effect of Vitis vinifera L seed extract on hepatic marker enzymes and oxidative stress against acetaminophen-induced hepatotoxicity in rats. International J ournal of Pharmaceutical and Chemical Sciences 2(2): 738743.

Rodriguez, C., Mayo, J.C., Sainz, R.M., Antolín, I., Herrera, F., Martín, V.and Reiter, R.J. (2004). Regulation of antioxidant enzymes: a significant role for melatonin. J. Pineal Res. 36: 1-9.

Sallinen, P., Saarela, S., Ilves, M., Vakkuri O., Leppäluoto, J. (2005). The expression of MT1 and MT2 melatonin receptor mRNA in several rat tissues. Life Sci. 21;76(10):1123-34

Tan, D.X., Reiter, R.J., Manchester, L.C., Yan, M.T., El Sawi, M., Sainz, R.M., Mayo, J.C., Kohen, R., Allegra, M. and Hardeland, R. (2002). Chemical and physical properties and potential mechanisms: Melatonin as a broad spectrum antioxidant and free radical scavenger. Curr. Top. Med. Chem. 2: 181-197.

Walter, R. B., Milano, F., Brasky, T. M. and White, E (2011). Long-term use of acetaminophen, aspirin, and other nonsteroidal anti-inflammatory drugs and risk of hematologic malignancies: results from the prospective Vitamins and Lifestyle (VITAL) study. J Clin Oncol. 29(17):2424-2431

Watkins, P.B. and Seef, L.B. (2006). Drug-induced liver injury: summary of a single topic clinical research conference Hepatology 43: 618-631.

Wong, L.T., Whitehouse, L.W., Solemonraj, G. and Paul, C.J . (1981). Pathways of disposition of acetaminophen conjugates in the mouse Toxicity Lett. 9: 145-151.

Yakubu, N, Oboh, G, and Olalekan, A. A. (2013). Antioxidant and hepatoprotective properties of Tofu (Curdle Soymilk) against acetaminopheninduced liver damage in rats. Biotech Res Int. doi: $10.1155 / 2013 / 230142$ 